\title{
Land Use Transformation Rule Analysis in Beijing-Tianjin-Tangshan Region Using Remote Sensing and GIS Technology
}

\author{
Shang-min Zhao, ${ }^{1}$ Wei-ming Cheng, ${ }^{2}$ Hai-jiang Liu, ${ }^{3}$ Yao Xia, ${ }^{2}$ Hui-xia Chai, \\ Yang Song, ${ }^{2}$ Wen-jie Zhang, ${ }^{2}$ and Tian You ${ }^{2}$ \\ ${ }^{1}$ Department of Surveying and Mapping, College of Mining Engineering, Taiyuan University of Technology, Taiyuan 030024, China \\ ${ }^{2}$ State Key Laboratory of Resources and Environmental Information System, \\ Institute of Geographic Sciences and Natural Resources Research, CAS, Beijing 100101, China \\ ${ }^{3}$ China National Environmental Monitoring Centre, Beijing 100012, China \\ ${ }^{4}$ Chinese Academy for Environmental Planning, Beijing 100012, China
}

Correspondence should be addressed to Shang-min Zhao; zhaoshangmin@tyut.edu.cn

Received 8 July 2014; Revised 12 January 2015; Accepted 14 January 2015

Academic Editor: Yongqiang Zhao

\begin{abstract}
Copyright (C) 2016 Shang-min Zhao et al. This is an open access article distributed under the Creative Commons Attribution License, which permits unrestricted use, distribution, and reproduction in any medium, provided the original work is properly cited.

Based on land use classification system, this paper acquires the land use distribution status at 2000, 2005, and 2010 in BeijingTianjin-Tangshan Region using remote sensing images, field survey data, images in Google Earth, and visual interpretation methods. Then, the land use transformation rules from 2000 to 2010 are achieved using GIS (geographic information system) technology. The research results shows the following: (1) as to the distribution area of the land use types, dry field has the largest area, followed by forest land, building land, paddy field, water area, grassland, and unused land; (2) from 2000 to 2010, the area of building land has the largest increase, which is mainly transformed from cropland and sea reclamation area; the largest decreased land use type is paddy field, which mainly transforms to dry field and building land; (3) the high increase of building land and decrease of cropland suggest the land use transformation in the quick development process of economy; meanwhile, the total area of forestland and grassland changes little, so the ecological environment does not have apparent deterioration in the 1st decade of the new century.
\end{abstract}

\section{Introduction}

As an important environmental element, land is a carrier for people's social and economic activities [1]. Land use means the result after people employing the land and its resources $[2,3]$, so its distribution status and dynamic change have important impact not only on land management practices, economic, and social developing processes, but also on government policy at regional, national, and even global level [4, 5]. Land use change is an important element of environmental change processes, which has much significance in sustainable development processes [6] so as to become one of the hot research fields.

With the development of science and technology, land use change monitoring is widely conducted by using remote sensing and geographic information system (GIS) technologies [7]. Remote sensing images are used to acquire the land use status at different phases $[8,9]$; based on multitemporal land use data, GIS technology has been proved to be an efficient method to conduct land use dynamic monitoring, transformation rule acquisition, spatial-temporal pattern analysis, and so on [10-12].

As China's capital, Beijing, is a political, cultural, and economic center in China, so it has unique land use characteristics after long-term comprehensive action of natural and humanity factors [13]. Tianjin is the biggest coastal open city in northern China, which is adjoining to Bohai Sea; with fast development of the economy, land use in Tianjin faces severe transformation, especially in coastal area, where large sea area changes to sea reclamation area, such as building 


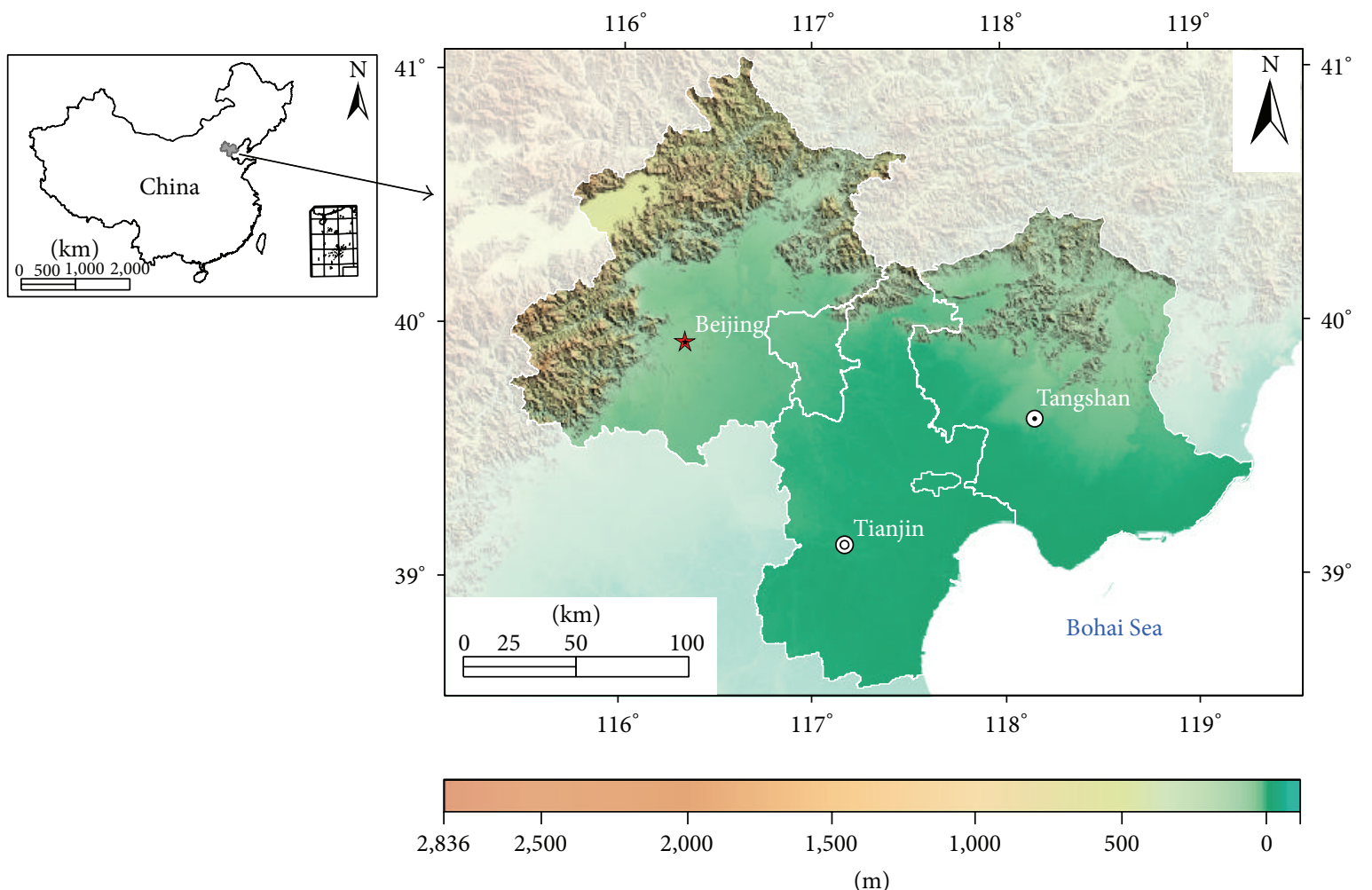

FIGURE 1: Location and relief map of the study area.

land and water area [14]. Tangshan is a central city in Hebei Province, which surrounds the central Bohai gulf region, so it is the strategic place and extremely important corridor for adjoining North China Region and Northeast China Region [15]. Tangshan combined with Beijing and Tianjin forms an important metropolitan circle in China, Beijing-TianjinTangshan metropolitan circle, which is defined as BeijingTianjin-Tangshan Region in this research. Compared to other metropolitan circles, Beijing-Tianjin-Tangshan metropolitan circle has relatively lower research degree [16]. The fast development of economy, deep opening-up policy, infrastructure modernization at highest level, and especially the site for 2008 Olympic Games in Beijing make it essential to monitor the transformation rule of land use in this region.

Hence, this research firstly collected and processed remote sensing images in Beijing-Tianjin-Tangshan Region at different phases; then land use distribution status in 2000, 2005, and 2010 were visually interpreted in the study region by using remote sensing images; finally, the land use transformation rules from 2000 to 2010 are acquired and analyzed by using spatial analysis function in ArcGIS software. It has scientific, economic, and environmental significance at some extent for acquiring the land use distribution status and transformation rules from 2000 to 2010 in Beijing-TianjinTangshan Region.

\section{Study Area}

This research chooses Beijing-Tianjin-Tangshan metropolitan economic circle as the study area, which includes China's capital, Beijing, municipality directly under the Central
Government, Tianjin, and northern part of Hebei Province, Tangshan City. Additionally, in order to avoid hollow area, the study area also includes some counties of Langfang City in Hebei Province. As the geographic boundary of the study area extends from $115.4^{\circ} \mathrm{E}$ to $119.3^{\circ} \mathrm{E}$ and from $38.6^{\circ} \mathrm{N}$ to $41.1^{\circ} \mathrm{N}$, the Albers Equal Area projection with two standard parallels of $25^{\circ} \mathrm{N}$ and $47^{\circ} \mathrm{N}$ and central meridian of $117^{\circ} \mathrm{E}$ is chosen as the uniform projection in this research, which considers minimum deformation, area statistics, and consistency to national projection (Figure 1).

The study area locates in the northern part of North China Plain, which is the transition area between North China Region and Northeast China Region. With Yanshan Mountains to the north, Taihangshan Mountains to the west, and Bohai Sea to the east, the geographical location of the study area has much significance (Figure 1).

The main distribution of coastal plain and semiwet monsoon climate make the study area not only an important grain production base, but also a fast developing metropolitan economic circle. The fast development of the economy, establishment of the national central cities, and the Beijing Olympic Games make the land use distribution here transform severely. So it is important to conduct land use transformation rule research in the study area, which is significant to understand the ecological and environmental change in this period.

\section{Material and Methodology}

The main data sources used in this research are remote sensing images in 2000, 2005, and 2010. Additionally, field 


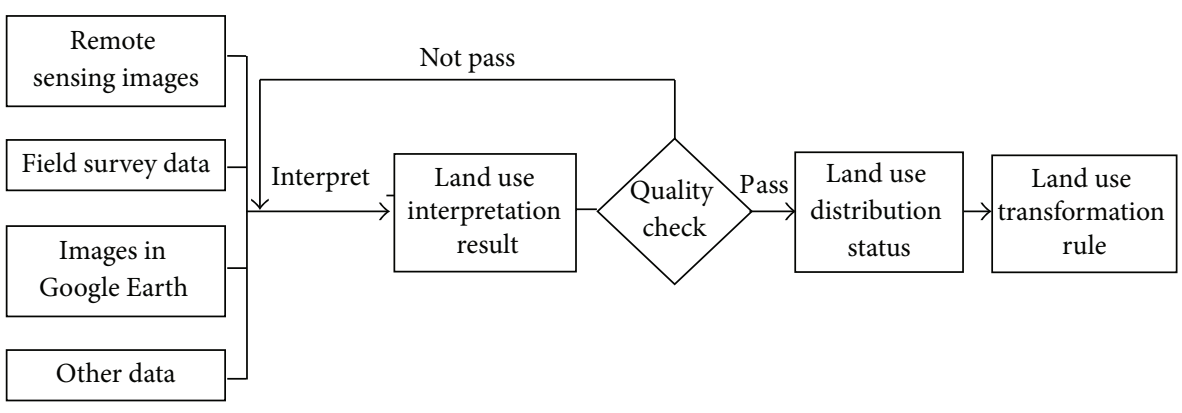

FIgURE 2: Work flow of this research.

survey data, topographic maps, images in the Google Earth, vegetation data, and geomorphologic data, and so on are also referenced.

The main data sources and the methodology in this research are specifically illustrated in the following.

3.1. Remote Sensing Images. The main remote sensing images are Landsat TM images in 2000, 2005, and 2010. The images are mostly collected in summer season (especially August) to decrease the weather influences. The path-rows of the images in the study area are 121-031, 121-033, 122-032, 122-033, 123032, 123-033, and 124-032, respectively.

The remote sensing images in 2000 are processed through data selection, downloading, band selection and stack, atmospherically correction, geometric correction based on topographic maps at 1:50,000 scales, mosaic, projection, clip, and so on [17]. The processes to the remote sensing images in 2005 and 2010 are similar to these in 2000, except for that the geometric corrections are based on the processed images in 2000 .

3.2. Methodology. Many researchers have tried to acquire land use change status by using remote sensing images $[5,7$, 17-19], so several techniques for achieving dynamic monitoring of land use have been proposed, applied, and evaluated, such as principle component analysis [20, 21], comparison among two or more images at different phases and so on [2225]. These techniques mainly aim at the automatic extraction of the land use information, as to the extraction quality, the traditional visually interpretation method combined with field survey data has the highest quality and accuracy, despite of large labour, time, and money input. Hence, the visual interpretation method is adopted in this research.

The remote sensing images are the fundamental data for acquiring the land use distribution status at different phases. The processed images are mainly Landsat TM images, which have 7 bands, and the usual band combination in the land use interpretation is 4-3-2 presented by red, green, and blue colour; sometimes, other band combinations are also used, such as 7-4-2 and 5-4-3. Meanwhile, other auxiliary data are also used in land use visual interpretation, such as the images in the Google Earth with higher spatial resolution, the field survey data with field pictures, land use types and locations, the Chinese geomorphologic data, and the vegetation data at $1: 1,000,000$ scales.
Under the ArcGIS software, the land use distribution status is visually interpreted by using multidata sources, especially the remote sensing images. According to the interpretation results of the land use distribution status, the land use transformation rules from 2000 to 2010 are acquired and analyzed. Thus, the work flow of this research is shown in the Figure 2.

The accuracy of the interpretation results is fundamental in this research, which also affects the quality of the land use transformation rules. In 2008, 2009, and 2010, about 400 sample points are checked. Through field survey, the locations, pictures, and land use types are acquired for these sample points. Based on these points, the accuracy of the interpretation results is estimated for higher than $85 \%$. Finally, the interpreted results are revised according to the filed survey results of these sample points.

\section{Analysis to the Distribution Statuses of Land Use in 2000, 2005, and 2010}

Based on the visual interpretation results for the remote sensing images, the land use distribution statuses are acquired in 2000, 2005, and 2010 in the study area, which are analyzed, respectively, as in the following.

4.1. Analysis to the Distribution Status of Land Use in 2000. Based on the data sources and the methodology, land use distribution status in 2000 is interpreted in the study area, which is shown in Figure 3(a).

In Figure 3, the legend gives the land use types represented by different numbers. The representations keep consistency in this research. Through area statistics to every land use type, the results are shown in Table 1.

Figure 3(a) and Table 1 show the land use distribution status in 2000 in the study area: dry field is the most widely distributed type, which mainly distributes in the central and southern flat part; then forestland is distributing mainly in the western and northern mountainous and hill region; the next is building land, including mainly residential areas at all levels and coastal areas; paddy field mainly distributes in the eastern part, especially the northeastern part; other land use types, such as water area, grassland, and unused land, are the least distributed types; water area mainly distributes in lakes, ponds, and channels; as to grassland, it mainly distributes in the northern hill areas. 


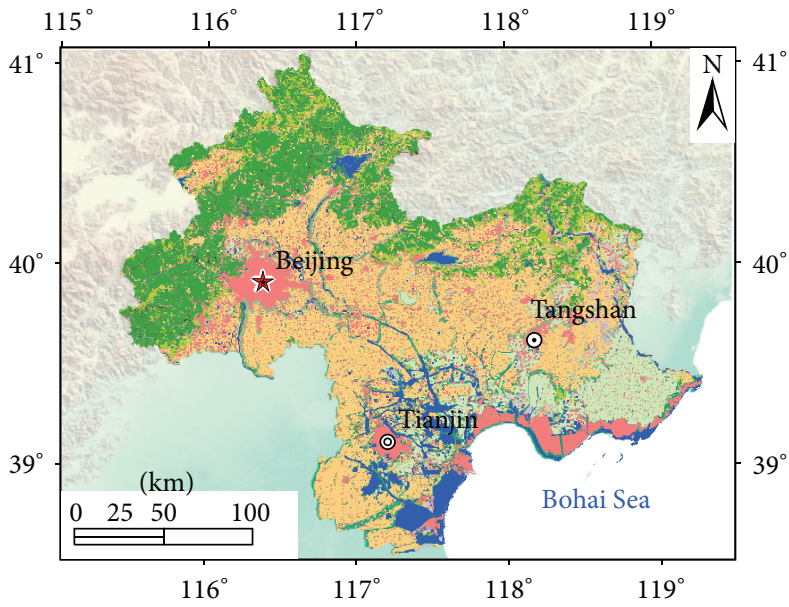

(a)

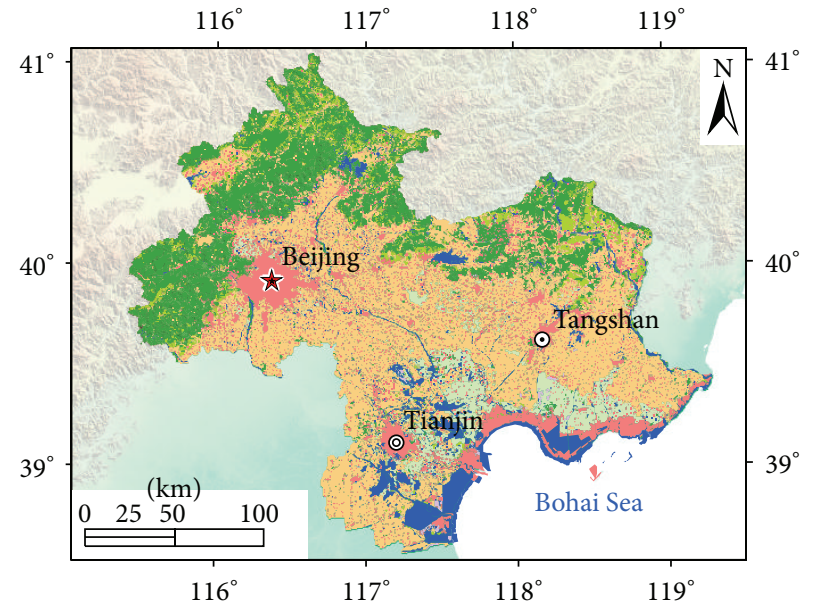

(b)

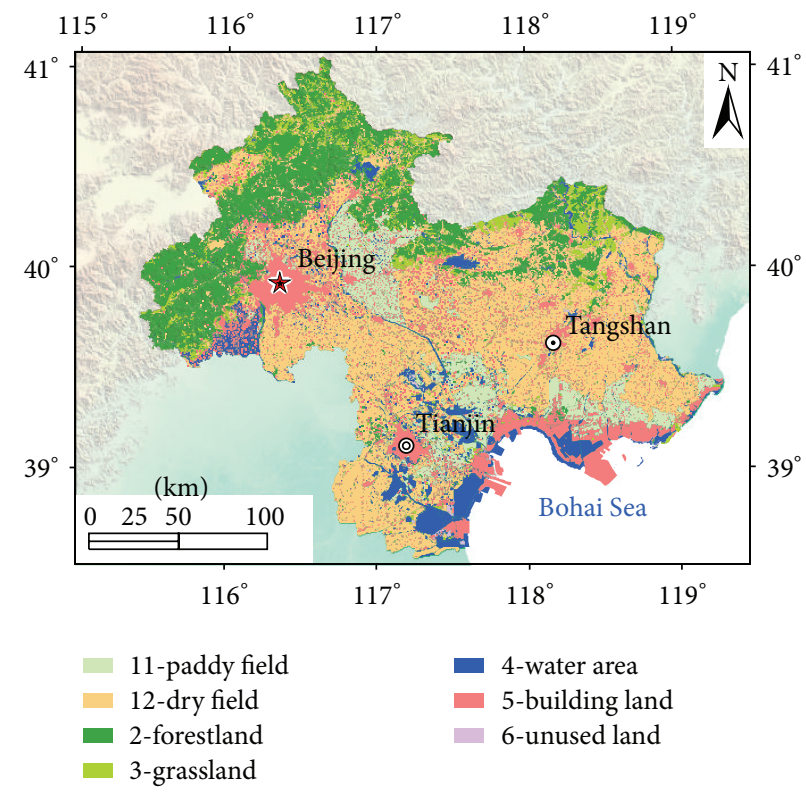

(c)

Figure 3: Land use distribution status in different phases ((a) 2000; (b) 2005; (c) 2010).

TABLE 1: Area statistics of land use types in 2000, 2005, and $2010\left(\times 10^{4} \mathrm{~km}^{2}\right)$.

\begin{tabular}{cccccccccc}
\hline \multirow{2}{*}{ Time } & $\begin{array}{c}\text { Land cover } \\
\text { type }\end{array}$ & Paddy field & Dry field & Forestland & Grassland & Water area & Building land & Unused land & Total \\
\hline \multirow{2}{*}{2000} & Area & 4403.7 & 16280.7 & 9251.6 & 2627.8 & 3169.9 & 6667.8 & 500.0 & 42901.5 \\
& Ratio & $10.3 \%$ & $37.9 \%$ & $21.6 \%$ & $6.1 \%$ & $7.4 \%$ & $15.5 \%$ & $1.2 \%$ & $100 \%$ \\
\hline \multirow{2}{*}{2005} & Area & 2744.7 & 17796.4 & 10001.3 & 2287.3 & 3484.4 & 6765.2 & 160.5 & 43239.8 \\
& Ratio & $6.3 \%$ & $41.2 \%$ & $23.1 \%$ & $5.3 \%$ & $8.1 \%$ & $15.6 \%$ & $0.4 \%$ & $100 \%$ \\
\hline \multirow{2}{*}{2010} & Area & 3754.8 & 16492.6 & 9499.8 & 2384.4 & 3626.4 & 7634.5 & 129.1 & 43521.6 \\
& Ratio & $8.6 \%$ & $37.9 \%$ & $21.8 \%$ & $5.5 \%$ & $8.3 \%$ & $17.5 \%$ & $0.3 \%$ & $100 \%$ \\
\hline
\end{tabular}

4.2. Analysis to the Distribution Status of Land Use in 2005. Through visual interpretation and revision, land use distribution status in 2005 can be acquired by using remote sensing images in 2005 and referencing the land use distribution results in 2000. After passing quality check, the land use distribution results in 2005 in the study area are shown in Figure 3(b). The area and ratio of the land use types in 2005 are computed, which are shown in Table 1. 
TABLE 2: Land use transformation area from 2000 to $2005\left(\times 10^{4} \mathrm{~km}^{2}\right)$.

\begin{tabular}{|c|c|c|c|c|c|c|c|c|c|}
\hline \multirow{2}{*}{2000} & \multicolumn{9}{|c|}{2005} \\
\hline & Void & Paddy field & Dry field & Forestland & Grassland & Water area & Building land & Unused land & Sum \\
\hline Void & 0.0 & 0.0 & 0.4 & 0.0 & 0.0 & 300.0 & 39.6 & 0.0 & 340.1 \\
\hline Paddy field & 0.0 & 2136.3 & 1856.5 & 57.6 & 39.5 & 76.3 & 200.1 & 38.7 & 4405.0 \\
\hline Dry field & 0.0 & 312.3 & 14026.7 & 682.0 & 261.3 & 235.6 & 755.7 & 7.4 & 16280.9 \\
\hline Forestland & 4.0 & 6.6 & 401.8 & 8263.2 & 463.6 & 34.4 & 76.1 & 1.9 & 9251.6 \\
\hline Grassland & 0.0 & 40.5 & 235.9 & 828.3 & 1445.3 & 30.4 & 43.9 & 3.6 & 2627.8 \\
\hline Water area & 0.0 & 125.3 & 271.7 & 70.1 & 28.5 & 2474.6 & 185.9 & 13.7 & 3170.0 \\
\hline Building land & 0.3 & 81.6 & 692.6 & 80.5 & 42.1 & 324.9 & 5441.7 & 4.9 & 6668.7 \\
\hline Unused land & 0.0 & 42.1 & 310.9 & 19.5 & 6.9 & 8.1 & 22.1 & 90.2 & 500.0 \\
\hline Sum & 4.3 & 2744.7 & 17796.4 & 10001.3 & 2287.3 & 3484.4 & 6765.2 & 160.5 & 43244.1 \\
\hline
\end{tabular}

Figure 3(b) and Table 1 show the distribution status of land use in 2005: the whole land use distribution status in 2005 is similar to it in 2000 . As to the specifics, the total area has increased $338.3 \mathrm{~km}^{2}$, which is mainly due to the added coastal land adjoining to the Bohai Sea; the areas of dry field and forestland increase remarkably; inversely, the areas of paddy field, unused land, and grassland decrease evidently; as to other land use types, the distribution of building land and water area does not have apparent change.

4.3. Analysis to the Distribution Status of Land Use in 2010. Referencing the visually interpreted land use distribution results in 2000 and 2005, the land use distribution status in 2010 in the study area is visually interpreted based on remote sensing images and auxiliary data, which is shown in Figure 3(c). Through computing the area of every land use types in 2010, the statistics results are shown in Table 1.

From Figure 3 and Table 1 we can see that the whole land use distribution status in 2010 is similar to them in 2000 and 2005. Compared to the land use distribution statuses in 2000 and 2005, the land use distribution status in 2010 has the following changes: the total area continuously increases from 2000 to 2010, which is mainly due to the coastal construction; the area of paddy field increases from 2005 to 2010 but decreases from 2000 to 2010; the area of dry field decreases from 2005 to 2010 but has a little increase from 2000 to 2010; the area of forestland decreases from 2005 to 2010 but increases a little from 2000 to 2010; the area of grassland has evident decrease from 2000 to 2010; the area of water area consistently increases from 2000 to 2010; the area of building land also consistently increases from 2000 to 2010, especially from 2005 to 2010; the area of unused land consistently decreases from 2000 to 2010, which shows the rapid change of land use distribution status.

\section{Analysis to the Transformation Rules of Land Use from 2000 to 2010}

Land use transformation is due to that one land use type in this phase may transform to other land use types in the later phase. So land use transformation status is mainly acquired by calculating the land use transformation areas of every land use type during two phases. Usually, the transformations between every two land use types are mutual-transformative, such that the paddy field may transform to the dry field and vice versa during two phases. In order to eliminate the mutual-transformative situations, the absolute transformation status is presented and defined, which is acquired by computing the subtraction of the roll-out and roll-in area for every land use type during two phases.

Hence, based on the land use distribution statuses in 2000,2005 , and 2010 in the study area, the land use transformation statuses from 2000 to 2005, from 2005 to 2010, and from 2000 to 2010 are computed and analyzed based on GIS spatial analysis function; moreover, the absolute transformation status is acquired and analyzed from 2000 to 2010 for every land use type.

5.1. Analysis to the Transformation Status of Land Use from 2000 to 2005. The land use transformation status from 2000 to 2005 can be computed by overlapping the land use distribution results of 2000 and 2005. As the distribution areas for 2000 and 2005 do not completely coincide, union function is used instead of clipping function. The processed land use transformation distribution status from 2000 to 2005 in the study area is shown as in Figure 4(a).

In Figure 4(a), the number before the short line represents the land use type in 2000, the early phase; the number after the short line represents the land use type in 2005, the latter phase. The land use types represented by these numbers can be retrieved in Figure 3. For the number "0," it represents that the land use type does not exist in the corresponding phase but exists in other phase; this region mainly exists in Bohai Sea and is defined as sea reclamation area.

Making an area statistic to the land use transformation types, the computed results are shown in Table 2.

In Table 2, the right column gives the areas of land use types in 2000; the lowest line shows the areas of land use types in 2005; middle part shows the land use transformation status; the void type corresponds to the " 0 " number in Figure 4.

Figure 4(a) and Table 2 show that, from 2000 to 2005, paddy field mainly transforms to dry field, so the area of paddy field decreases and that of dry field increases; the forestland mainly originates from grassland and dry land, so the area of the forestland increases and that of the grassland 


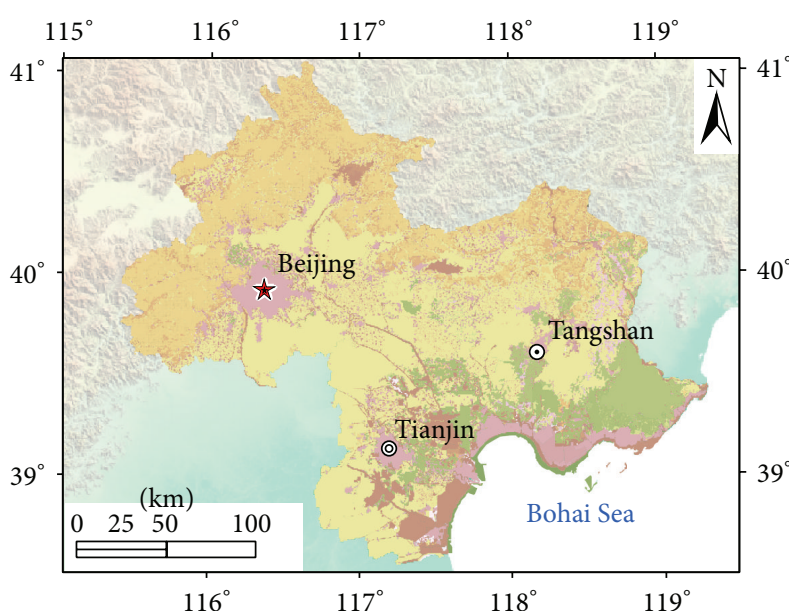

(a)

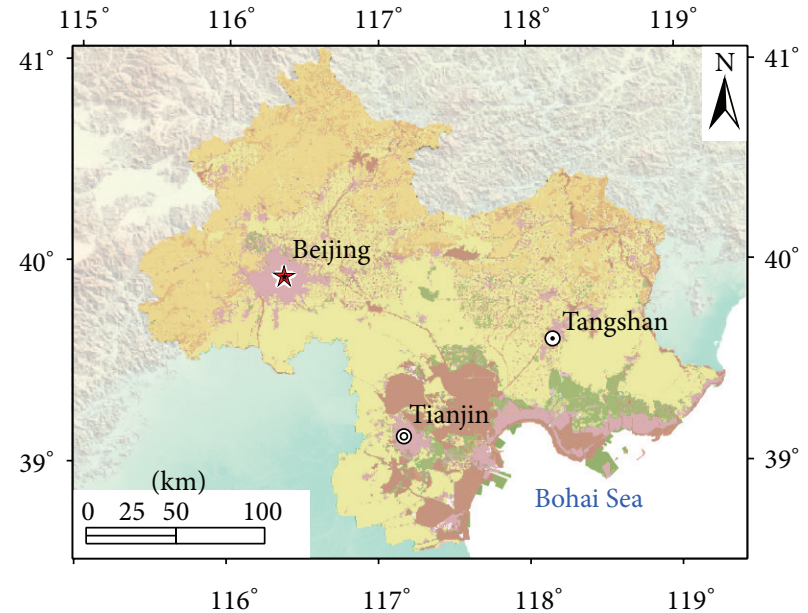

(b)

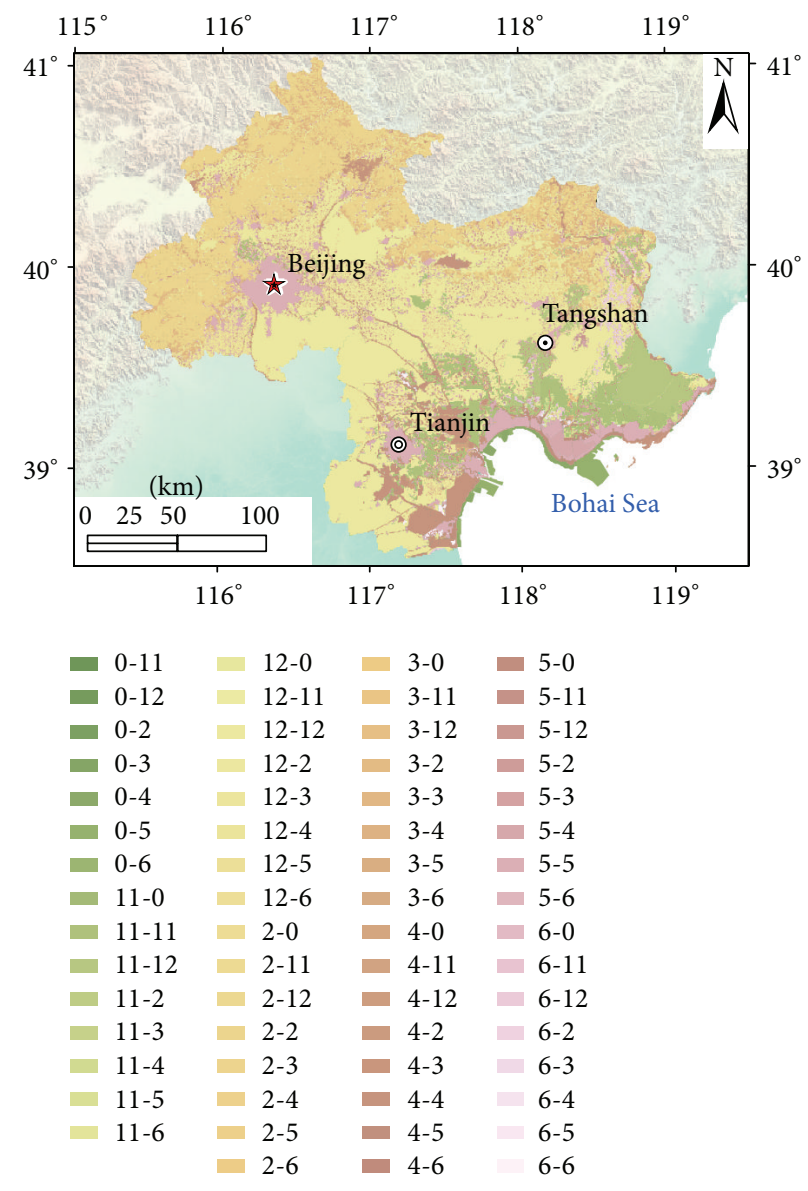

(c)

FIgURE 4: Land use transformation status from 2000 to 2010 ((a) from 2000 to 2005; (b) from 2005 to 2010; (c) from 2000 to 2010 ).

decreases. The unused land mainly transforms to the dry field. Undoubtedly, the transformed dry field from unused land has low quality.

5.2. Analysis to the Transformation Status of Land Use from 2005 to 2010. Processing the land use distribution statuses in both 2005 and 2010 by union function, the land use transformation status from 2005 to 2010 can be achieved as shown in Figure 4(b). The explanation to Figure 4(b) can reference them for Figure 4(a). Making an area statistics to the land use transformation status in Figure 4(b), the results are shown as in Table 3. 
TABLE 3: Land use transformation area from 2005 to $2010\left(\times 10^{4} \mathrm{~km}^{2}\right)$.

\begin{tabular}{|c|c|c|c|c|c|c|c|c|c|}
\hline \multirow{2}{*}{2005} & \multicolumn{9}{|c|}{2010} \\
\hline & Void & Paddy field & Dry field & Forestland & Grassland & Water area & Building land & Unused land & Sum \\
\hline Void & 0.0 & 0.0 & 0.0 & 4.0 & 2.6 & 63.7 & 247.0 & 0.0 & 317.3 \\
\hline Paddy field & 0.0 & 2340.9 & 176.7 & 5.5 & 3.5 & 13.7 & 203.4 & 0.9 & 2744.7 \\
\hline Dry field & 0.0 & 1249.4 & 14952.0 & 275.1 & 130.6 & 500.8 & 678.1 & 10.3 & 17796.4 \\
\hline Forestland & 0.0 & 10.5 & 600.3 & 8975.0 & 297.2 & 38.4 & 72.8 & 7.1 & 10001.3 \\
\hline Grassland & 0.0 & 4.1 & 198.1 & 189.1 & 1856.8 & 10.0 & 25.2 & 4.1 & 2287.3 \\
\hline Water area & 32.9 & 29.8 & 134.3 & 17.2 & 46.5 & 2958.0 & 250.8 & 14.9 & 3484.4 \\
\hline Building land & 0.1 & 96.4 & 418.6 & 28.3 & 39.6 & 36.9 & 6139.0 & 6.3 & 6765.2 \\
\hline Unused land & 0.0 & 24.1 & 12.7 & 5.7 & 7.5 & 5.1 & 20.0 & 85.5 & 160.5 \\
\hline Sum & 33.0 & 3755.1 & 16492.8 & 9499.8 & 2384.4 & 3626.4 & 7636.4 & 129.1 & 43557.1 \\
\hline
\end{tabular}

TABLE 4: Land use transformation area from 2000 to $2010\left(\times 10^{4} \mathrm{~km}^{2}\right)$.

\begin{tabular}{|c|c|c|c|c|c|c|c|c|c|}
\hline \multirow{2}{*}{2000} & \multicolumn{9}{|c|}{2010} \\
\hline & Void & Paddy field & Dry field & Forestland & Grassland & Water area & Building land & Unused land & Sum \\
\hline Void & 0.0 & 0.0 & 0.1 & 0.0 & 2.6 & 230.0 & 391.6 & 0.0 & 624.3 \\
\hline Paddy field & 0.0 & 2057.7 & 1790.9 & 32.7 & 28.8 & 66.9 & 423.8 & 3.0 & 4403.8 \\
\hline Dry field & 0.0 & 1337.4 & 12762.1 & 340.9 & 220.7 & 611.4 & 994.0 & 14.3 & 16280.8 \\
\hline Forestland & 0.0 & 18.9 & 308.3 & 8292.0 & 510.7 & 37.7 & 76.6 & 7.3 & 9251.5 \\
\hline Grassland & 0.0 & 34.0 & 289.6 & 699.9 & 1506.2 & 33.2 & 59.4 & 5.5 & 2627.8 \\
\hline Water area & 3.5 & 120.2 & 285.4 & 57.4 & 48.8 & 2332.3 & 304.6 & 17.8 & 3170.0 \\
\hline Building land & 0.6 & 162.8 & 734.4 & 65.2 & 60.7 & 304.9 & 5330.7 & 8.5 & 6667.8 \\
\hline Unused land & 0.0 & 23.9 & 321.9 & 11.9 & 5.8 & 9.9 & 53.9 & 72.6 & 499.9 \\
\hline Sum & 4.1 & 3754.9 & 16492.7 & 9500.0 & 2384.3 & 3626.3 & 7634.6 & 129.0 & 43526.0 \\
\hline
\end{tabular}

The explanation to Table 3 can reference them in Table 2. Figure 4(b) and Table 3 show that, from 2005 to 2010, paddy field and dry field have inverse change tendencies compared to them from 2000 to 2005; large area of dry field transforms to paddy field which leads to increase of paddy field and decrease of dry field; forestland mainly transforms to grassland and dry land, so the area of the forestland decreases, but the grassland increases. The area of building land has evident increase, which is mainly transformed from cropland and sea reclamation area.

5.3. Analysis to the Transformation Status of Land Use from 2000 to 2010. Overlapping land use distribution statuses in both 2000 and 2010 by union function, land use transformation status in whole period from 2000 to 2010 is computed as shown in Figure 4(c). The explanation to Figure 4(c) can reference them for Figure 4(a). Making an area statistics to the land use transformation types in Figure 4(c), the results are shown as in Table 4.

The explanation to Table 4 can reference them in Table 2. Figure 4(c) and Table 5 show that, from 2000 to 2010, paddy field mainly transforms to dry field and building land; dry field mainly transforms to paddy field, building land, and grassland; forestland mainly transforms to grassland and dry field; grassland mainly transforms to forestland and dry field; water area mainly transforms to building land and dry field; building land mainly transforms to dry field and water area; the area of unused land has evident decrease, which mainly transforms to dry field and building land.

5.4. Analysis to the Absolute Transformation of Land Use from 2000 to 2010. The above three subsections analyze transformation statuses in three periods which are from 2000 to 2005, from 2005 to 2010, and from 2000 to 2010. In the transformation statuses analysis, land use type transformation is mutual, so it is difficult to find the absolute transformation area between every two land use types. In view of this, the absolute transform area is computed to represent the subtraction area between the roll-out area and roll-in area for every two land use types, which is shown in Table 5.

In Table 5, the right column represents the areas of the land use types which transform to other land use types from 2000 to 2010; the lower line represents the areas of the land use types which are transformed from other land use types from 2000 to 2010; the middle part represents the absolute transformation areas between every two land use types.

Table 5 shows the absolute transformation status from 2000 to 2010 in the study area: the area of paddy field has the largest decrease, about $648.9 \times 10^{4} \mathrm{~km}^{2}$, which mainly transforms to dry field and the building land; on the contrary, building land has the largest increase, about $996.8 \times 10^{4} \mathrm{~km}^{2}$, which is mainly transformed from cropland (both paddy field and dry field); dry field has a little increase, which is because 
TABLE 5: Land use absolute transformation area from 2000 to $2010\left(\times 10^{4} \mathrm{~km}^{2}\right)$.

\begin{tabular}{|c|c|c|c|c|c|c|c|c|c|}
\hline \multirow{2}{*}{2000} & \multicolumn{9}{|c|}{2010} \\
\hline & Void & Paddy field & Dry field & Forestland & Grassland & Water area & Building land & Unused land & Sum \\
\hline Void & 0 & 0 & 0.1 & 0 & 2.6 & 226.5 & 391.0 & 0 & 620.2 \\
\hline Paddy field & 0 & 0 & 453.5 & 13.8 & -5.2 & -53.3 & 261.0 & -20.9 & 648.9 \\
\hline Dry field & -0.1 & -453.5 & 0 & 32.6 & -68.9 & 326 & 259.6 & -307.6 & -211.9 \\
\hline Forestland & 0 & -13.8 & -32.6 & 0 & -189.2 & -19.7 & 11.4 & -4.6 & -248.5 \\
\hline Grassland & -2.6 & 5.2 & 68.9 & 189.2 & 0 & -15.6 & -1.3 & -0.3 & 243.5 \\
\hline Water area & -226.5 & 53.3 & -326 & 19.7 & 15.6 & 0 & -0.3 & 7.9 & -456.3 \\
\hline Building land & -391.0 & -261.0 & -259.6 & -11.4 & 1.3 & 0.3 & 0 & -45.4 & -966.8 \\
\hline Unused land & 0 & 20.9 & 307.6 & 4.6 & 0.3 & -7.9 & 45.4 & 0 & 370.9 \\
\hline Sum & -620.2 & -648.9 & -211.9 & 248.5 & -243.5 & 456.3 & 966.8 & 370.9 & 0 \\
\hline
\end{tabular}

lots of paddy field and unused land transform to dry field, but part of dry filed transforms to building land; the increase of forestland and decrease of grassland are mainly due to that part of grassland transforms to forestland, about $189.2 \times$ $10^{4} \mathrm{~km}^{2}$; water area has an evident increase which mainly originates from the sea reclamation area; for the unused land, it has large decrease which mainly transforms to dry field; large area of the sea reclamation area is utilized, which mainly transforms to the building land and water area. As part of water area also which belongs to the building land, such as ponds in the parks, the area of the building land increases even larger; the large increase of building land and decrease of cropland show the rapid change of land use in the economy development process; meanwhile, large area of paddy field transforms to dry field and building land, which represents the deterioration situation of the cropland in both quality and quantity aspects. The change of forestland and grassland shows that the ecological environment does not change worse which may result from large campaigns in the study area, such as the Olympic Games in 2008.

\section{Discussion}

This research has some breakthroughs in the land use transformation rule analysis from 2000 to 2010 in the study area, but some improvements are also needed. So the innovations and prospects in this research are discussed in the following.

\subsection{Innovations}

(1) Significant Study Area. Compared to other researches, this research selects the Beijing-Tianjin-Tangshan metropolitan circle in China as the study area, which has much larger area than the study regions in other researches $[10,26$, 27]. Moreover, the deep opening-up and reform policy, fast development of the economy, and hosting site for Olympic Games in 2008 make the study area in this research have much significance and necessary to make a land use dynamic research.

(2) Land Use Distribution Acquisition Method. This research selects traditional remote sensing method, visually interpretation combined with field survey data to acquire the land use distribution data. Although this method consumes large labour, time, and money, the acquired data have the highest accuracy at present situation [28]. Based on the sample points, the accuracy is estimated for higher than $85 \%$, which guarantees the quality and availability of the analyzed results.

(3) Achievement of the Land Use Transformation Rules. In most land use dynamic monitoring researches, land use distribution change matrix is usually adopted $[7,29]$, but the change matrix only gives the mutual transition status between every two land use types, and the absolute transition between every two land use types is seldom presented and analyzed. In this research, the achievement of the absolute transformation is helpful in understanding the real transformation status of the land use types.

\subsection{Research Prospects}

(1) Improvement of the Land Use Data. Although the authors had done their best to make the quality and accuracy of the land use data as high as possible, the data can also be improved in some aspects. For example, the land covered by water is classified as water area; sometimes, the classified water area should be changed to building land, such as pond, small lakes located in the building land. The improvement of the land use data will bring more reasonable results. Deep understanding of the land use situation and class system is important development of this research, which can be used to acquire better data.

(2) Further Analysis to the Land Use Data. The basic land use distribution data at three phases are acquired in this research, and the land use transformation rules are computed and analyzed in the study region from 2000 to 2010. However, the data can be studied much deeper in the future, such as acquiring the driving factors of the land use transformation [30], analyzing the spatial-temporal patterns of the land use distribution $[26,31]$, and so on.

\section{Conclusion}

From this research, the following conclusions can be drawn.

(1) In the study area, the distribution status of the land use types shows that dry field is the most widely 
distributed type and mainly distributes in central and southern part; then forestland is distributing mainly in western and northern mountainous and hill regions; the next is building land, including mainly residential areas at all levels and coastal areas; paddy field mainly distributes in the eastern part, especially the northeastern part; other land use types, including water area, grassland, and unused land, distribute sparsely.

(2) From 2000 to 2005 and then to 2010 , the area changes of land use types are as follows: dry field increases firstly and then decreases, whose area has a little increase in the whole period; forestland increases apparently firstly and then decreases, whose area has a small increase in the whole period; building land keeps increasing, especially from 2005 to 2010; paddy field decreases evidently firstly and then increases, whose area shows a decrease tendency in the whole period; grassland and unused land decrease remarkably; as to water area, it shows an increasing tendency, especially from 2005 to 2010.

(3) The land use transformation rule in the whole period is as follows: building land has the largest increase, which is mainly transformed from sea reclamation area, paddy filed, and dry field; conversely, paddy field has maximum decrease, which mainly transforms to dry filed and building land. The transformation rule of the land use types shows the rapid development of the economy and the deterioration situation of the cropland, in both quality and quantity aspects.

\section{Conflict of Interests}

The authors declare that there is no conflict of interests regarding the publication of this paper.

\section{Acknowledgments}

This research is under the auspices of the National Natural Science Foundation of China (41301469, 41171332), the Open Foundation of the LREIS, the National Science Technology Support Plan Project (2012BAH28B01-03), and the Qualified Personnel Foundation of Taiyuan University of Technology (QPFT) (tyut-rc201221a). The authors would like to express their sincere gratitude to the anonymous editors and referees.

\section{References}

[1] C. Lu, Q. Yang, Y. Tian, F. Wen, Y. Hu, and P. Wan, "Study on the driving force of land use based on the primary factor analysis," Journal of Anhui Agricultural Sciences, vol. 34, no. 21, pp. 56275628, 2006.

[2] W. B. Meyer, "Past and present land-use and land-cover in the USA," Consequences, vol. 1, pp. 25-33, 1995.

[3] G. S. Kiran and U. B. Joshi, "Estimation of variables explaining urbanization concomitant with land-use change: a spatial approach," International Journal of Remote Sensing, vol. 34, no. 3, pp. 824-847, 2013.

[4] D. S. Ojima, K. A. Galvin, and B. L. I. I. Turner, "The global impact of land-use change," BioScience, vol. 44, no. 5, pp. 300304, 1994.
[5] R. S. Dwivedi, K. Sreenivas, and K. V. Ramana, "Land-use/landcover change analysis in part of Ethiopia using Landsat Thematic Mapper data," International Journal of Remote Sensing, vol. 26, no. 7, pp. 1285-1287, 2005.

[6] X. Li, "A review of the international researches on land use/land cover change," Acta Geographica Sinica, vol. 51, no. 6, pp. 553557, 1996.

[7] X. Zhang, T. Kang, H. Wang, and Y. Sun, "Analysis on spatial structure of landuse change based on remote sensing and geographical information system," International Journal of Applied Earth Observation and Geoinformation, vol. 12, supplement 2, pp. S145-S150, 2010.

[8] J. Heo and T. W. FitzHugh, "A standardized radiometric normalization method for change detection using remotely sensed imagery," Photogrammetric Engineering and Remote Sensing, vol. 66 , no. 2, pp. 173-181, 2000.

[9] J. Rogan, J. Miller, D. Stow, J. Franklin, L. Levien, and C. Fischer, "Land-cover change monitoring with classification trees using Landsat TM and ancillary data," Photogrammetric Engineering and Remote Sensing, vol. 69, no. 7, pp. 793-804, 2003.

[10] J. G. Masek, F. E. Lindsay, and S. N. Goward, "Dynamics of urban growth in the Washington DC metropolitan area, 1973-1996, from Landsat observations," International Journal of Remote Sensing, vol. 21, no. 18, pp. 3473-3486, 2000.

[11] M. Herold, N. C. Goldstein, and K. C. Clarke, "The spatiotemporal form of urban growth: measurement, analysis and modeling," Remote Sensing of Environment, vol. 86, no. 3, pp. 286-302, 2003.

[12] D. Maktav and F. S. Erbek, "Analysis of urban growth using multi-temporal satellite data in Istanbul, Turkey," International Journal of Remote Sensing, vol. 26, no. 4, pp. 797-810, 2005.

[13] Y. He, Y. Chen, Z. Li, Y. Yao, and P. Tang, "Analysis on spatial structural characteristics of land use of Beijing City," Transactions of the Chinese Society of Agricultural Engineering, vol. 26, no. 2, pp. 313-318, 2010.

[14] N. Xu, W. Meng, F. Zhai, and H. Li, "Effects of land use change on ecosystem service value in Tianjin Binhai new area," Urban Environment and Urban Ecology, vol. 26, no. 1, pp. 5-8, 2013.

[15] X. Zhang, C. Chen, and K. Dong, "Analysis of temporal and spatial characteristics of land use pattern in Tangshan Coastal Zone from 1956 to 2005 based on RS and GIS," Acta Agriculturae Boreali-Occidentalis Sinica, vol. 22, no. 2, pp. 204-208, 2013.

[16] D. Meng, X. Li, H. Xu, and H. Gong, "The spatial expansion of construction land-use in Beijing-Tianjin-Hebei metropolis circle," Journal of Geo-Information Science, vol. 15, no. 2, pp. 289-296, 2013.

[17] Y.-Q. Zhao and J. Yang, "Hyperspectral image denoising via sparse representation and low-rank constraint," IEEE Transactions on Geoscience and Remote Sensing, vol. 50, no. 1, pp. 296308, 2015.

[18] T. Fung, "An assessment of TM imagery for land-cover change detection," IEEE Transactions on Geoscience and Remote Sensing, vol. 28, no. 4, pp. 681-684, 1990.

[19] E. F. Lambin and A. H. Strahler, "Change-vector analysis in multitemporal space: a tool to detect and categorize land-cover change processes using high temporal-resolution satellite data," Remote Sensing of Environment, vol. 48, no. 2, pp. 231-244, 1994.

[20] T. Fung and E. Ledrew, "Application of principal components analysis to change detection," Photogrammetric Engineering and Remote Sensing, vol. 53, no. 12, pp. 1649-1658, 1987. 
[21] J. R. Eastman and M. Fulk, "Long sequence time series evaluation using standardized principal components," Photogrammetric Engineering \& Remote Sensing, vol. 59, no. 6, pp. 991-996, 1993.

[22] K. Green, D. Kempka, and L. Lackey, "Using remote sensing to detect and monitor land-cover and land-use change," Photogrammetric Engineering and Remote Sensing, vol. 60, no. 3, pp. 331-337, 1994.

[23] O. E. Frihy, K. M. Dewidar, S. M. Nasr, and M. M. El Raey, "Change detection of the northeastern Nile Delta of Egypt: shoreline changes, spit evolution, margin changes of Manzala lagoon and its islands," International Journal of Remote Sensing, vol. 19, no. 10, pp. 1901-1912, 1998.

[24] K. M. Dewidar, "Landfill detection in Hurghada, North Red Sea, Egypt, using thematic mapper images," International Journal of Remote Sensing, vol. 23, no. 5, pp. 939-948, 2002.

[25] K. M. Dewidar, "Detection of land use/land cover changes for the northern part of the Nile delta (Burullus region), Egypt," International Journal of Remote Sensing, vol. 25, no. 20, pp. 4079-4089, 2004.

[26] D. Wang, J. Gong, L. Chen, L. Zhang, Y. Song, and Y. Yue, "Spatio-temporal pattern analysis of land use/cover change trajectories in Xihe watershed," International Journal of Applied Earth Observation and Geoinformation, vol. 14, no. 1, pp. 12-21, 2012.

[27] P. K. Mallupattu and J. R. Sreenivasula Reddy, "Analysis of land use/land cover changes using remote sensing data and GIS at an Urban Area, Tirupati, India," The Scientific World Journal, vol. 2013, Article ID 268623, 6 pages, 2013.

[28] S. Gao, Y. Cheng, and Y. Zhao, "Unsupervised change detection of satellite images using low rank matrix completion," Optics Letters, vol. 38, no. 23, pp. 5146-5149, 2013.

[29] Z. Li, X. Li, Y. Wang, A. Ma, and J. Wang, "Land-use change analysis in Yulin prefecture, northwestern China using remote sensing and GIS," International Journal of Remote Sensing, vol. 25, no. 24, pp. 5691-5703, 2004.

[30] D. Wang, J. Gong, L. Chenc, L. Zhang, Y. Song, and Y. Yue, "Comparative analysis of land use/cover change trajectories and their driving: forces in two small watersheds in the western Loess Plateau of China," International Journal of Applied Earth Observation and Geoinformation, vol. 21, no. 1, pp. 241-252, 2012.

[31] D. Ruelland, F. Levavasseur, and A. Tribotté, "Patterns and dynamics of land-cover changes since the 1960s over three experimental areas in Mali," International Journal of Applied Earth Observation and Geoinformation, vol. 12, supplement 1, pp. S11-S17, 2010. 


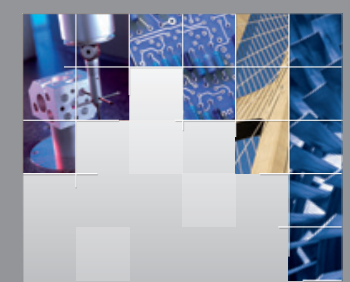

\section{Enfincering}
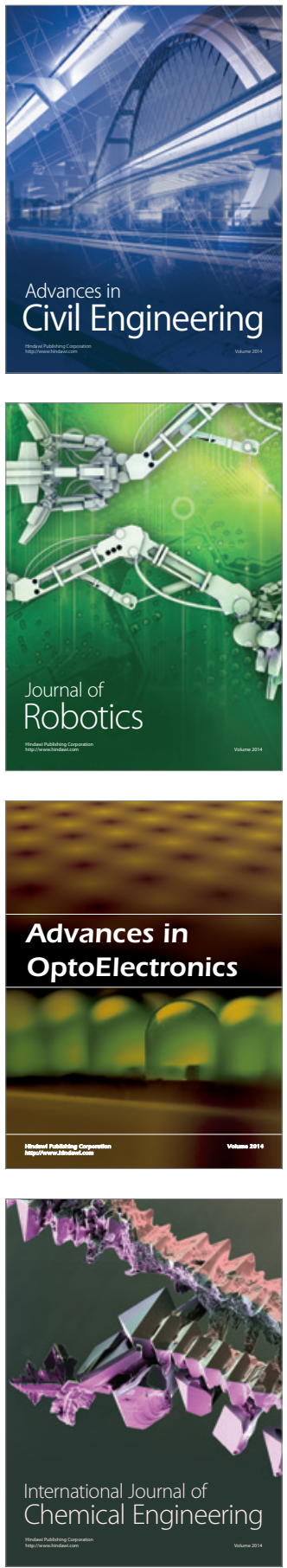

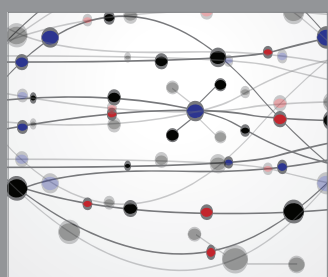

The Scientific World Journal

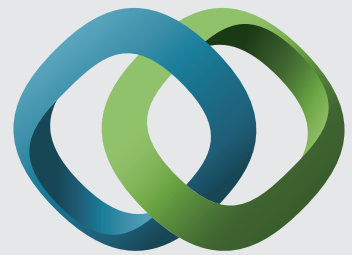

\section{Hindawi}

Submit your manuscripts at

http://www.hindawi.com
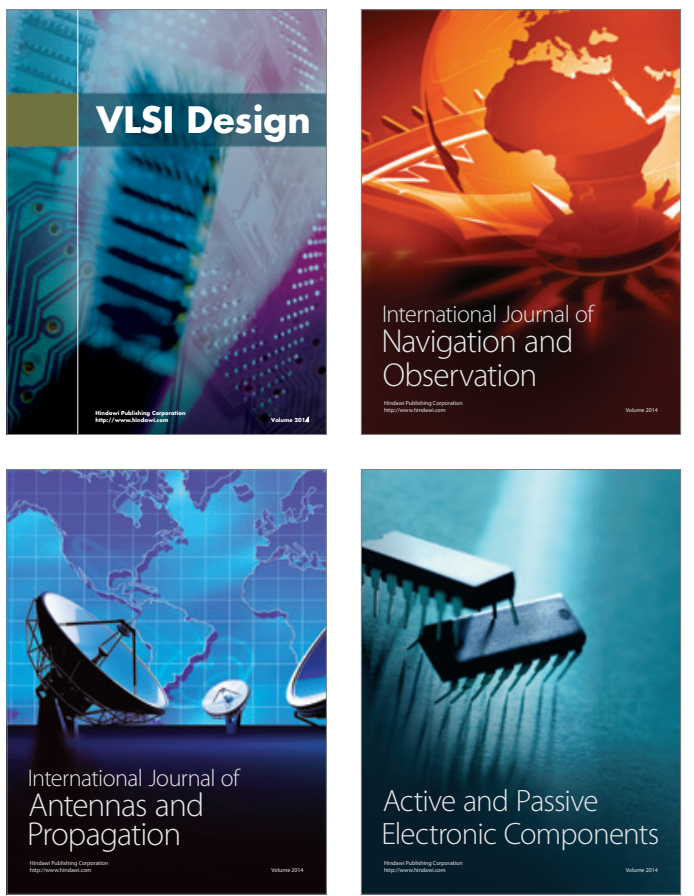
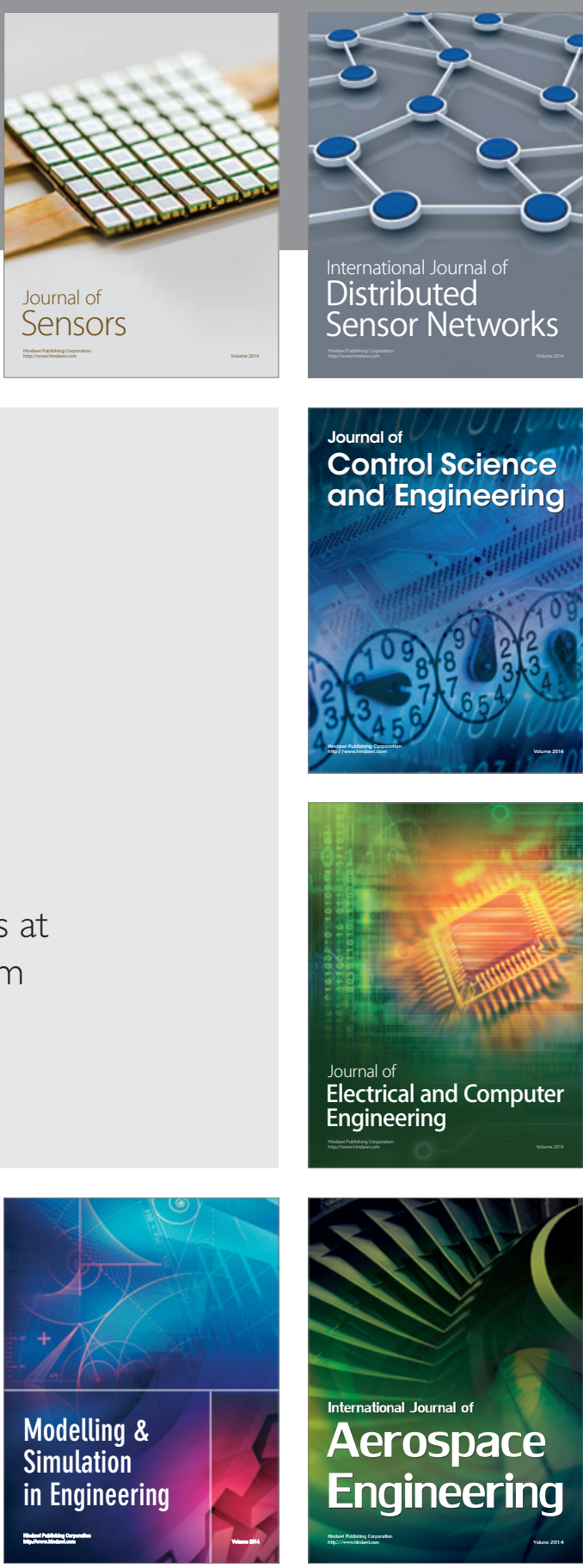

International Journal of

Distributed

Sensor Networks

Journal of

Control Science

and Engineering
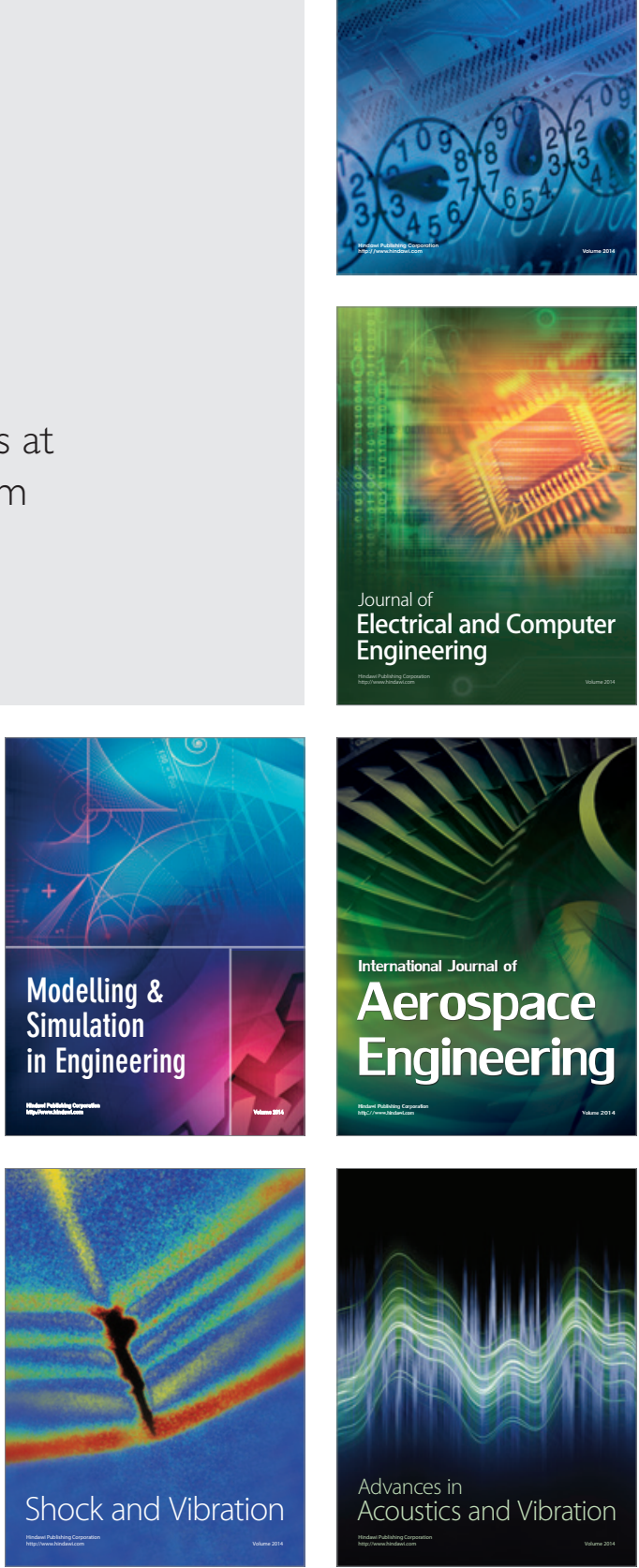